\title{
Cardiovascular Risk Assessment of Dyslipidemic Middle-Aged Adults without Overt Cardiovascular Disease over the Period of 2009-2016 in Lithuania
}

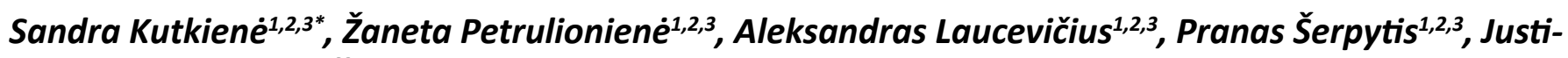

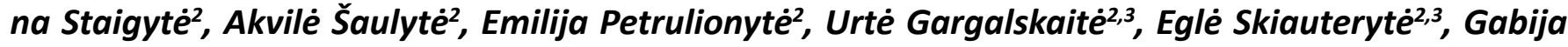

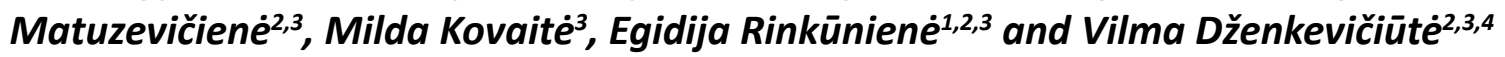

${ }^{1}$ Faculty of Medicine, Clinic of Cardiac and Vascular Diseases, Vilnius University, Lithuania

${ }^{2}$ Faculty of Medicine, Vilnius University, Lithuania

${ }^{3}$ Vilnius University Hospital Santaros Klinikos, Lithuania

${ }^{4}$ Faculty of Medicine, Clinic of Internal Diseases, Family Medicine and Oncology, Vilnius University, Lithuania

*Corresponding author: Sandra Kutkienè, Vilnius University Hospital Santaros Klinikos, Santariskiu g. 2, 08661, Vilnius, Lithuania, Tel: +370-5-2365307, E-mail: sandra.kutkiene@santa.It

\begin{abstract}
Background: Cardiovascular mortality in Lithuania is extremely high and abnormal lipid levels are very common among Lithuanian adults. Dyslipidemia is one of the main independent risk factors for cardiovascular diseases (CVD) leading to high absolute CVD risk. The aim of this study was to assess CVD risk in dyslipidemic middle-aged subjects.

Methods: During the period of 2009-2016 a total of 92373 people (58.4\% women and $41.6 \%$ men) were evaluated. This study included men aged 40-54 and women aged 5064 without overt CVD.

Results: Any type of dyslipidemia was present in $89.7 \%$ of all study population. $7.5 \%$ of dyslipidemic patients did not have any other conventional risk factors. Three and more risk factors were detected in $60.1 \%$ of dyslipidemic subjects. All analyzed risk factors, except smoking, were more common in dyslipidemic adults compared to subjects without dyslipidemia: Arterial hypertension ( $55.8 \%$ vs. $43.3 \%, p<0.001)$, diabetes $(11.1 \%$ vs. $7.3 \%, p<0.001)$, abdominal obesity $(45.3 \%$ vs. $30.2 \%, p<0.001), \mathrm{BMI} \geq 30 \mathrm{~kg} / \mathrm{m}^{2}(35.8 \%$ vs. $23.7 \%, \mathrm{p}$ $<0.001)$, metabolic syndrome $(34.0 \%$ vs. $9.2 \%$, p < 0.001$)$, family history of coronary heart disease $(26.3 \%$ vs. $23.1 \%$, $p<0.001)$, unbalanced diet $(62.5 \%$ vs. $52.9 \%, p<0.001)$ and insufficient physical activity $(52.0 \%$ vs. $44.2 \%, p<0.001)$. The prevalence of all evaluated risk factors, except smoking, increased with age. Average SCORE index was 1.87 in all study population, while dyslipidemic subjects had higher SCORE compared to control group (1.95 vs. $1.20, p<0.001)$.
\end{abstract}

\begin{abstract}
Conclusions: Almost two thirds of dyslipidemic middle-aged Lithuanian adults without overt cardiovascular disease had three or more other CVD risk factors, which synergistically increase absolute risk of CVD. The average 10-year risk of CVD death in patients with dyslipidemia was $1.95 \%$. The importance of managing dyslipidemia as well as other risk factors in order to reduce burden of cardiovascular disease in Lithuania is evident.
\end{abstract}

\section{Keywords}

Dyslipidemia, Cardiovascular risk, Primary prevention, Clustering of risk factors, Middle-aged population, Score

\section{Introduction}

Cardiovascular disease (CVD) is a major cause of premature death in Lithuania as more than a half of all deaths (56.2\%) were caused by CVD in 2016 [1]. Our country has the highest level of deaths from coronary heart disease (CHD) in Europe [2] and is classified as high-risk country in 2016 European guidelines on CVD prevention [3]. The main risk factors for CVD are elevated levels of blood lipids, high blood pressure, tobacco use, diabetes mellitus, unhealthy eating habits, low physical activity, overweight and obesity [4].

Dyslipidemia is one of the most important modifiable 
risk factors described more than half a century ago [5]. The association between increased lipid concentrations and the risk of CVD is well established [6] and the causal relationship is supported by strong epidemiological evidence of efficacy of lipid lowering therapy in reducing the incidence of CHD [7]. Dyslipidemia is often found together with multiple other cardiovascular risk factors, especially hypertension and obesity [8]. It is well known that coexisting multiple risk factors tend to increase the CVD risk synergistically because of additional adverse effect on the vascular endothelium $[9,10]$. Estimated prevalence of dyslipidemia in Lithuania is very high (88.8\%) according to Lithuanian High Cardiovascular Risk programme data analysis [11].

It is settled that prevention is effective in reducing the impact of CVD and one of the main measures is lowering increased levels of modifiable cardiovascular risk factors [12]. Despite positive changes in prevalence of adult arterial hypertension $(\mathrm{AH})$ in Lithuania, the cardiovascular risk of the population still remains high $[13,14]$. While continuing the positive trends, nowadays all the efforts should be focused on management of dyslipidemia. The aim of our study was to assess cardiovascular risk profile of middle-aged Lithuanian adults with and without dyslipidemia in order to broadly analyze the importance of this major CVD risk factor.

\section{Methods}

\section{Study population and measurements}

The Lithuanian High Cardiovascular Risk (LitHiR) primary prevention programme, funded by the Ministry of Health, was started in 2006. The Local Research Ethics Committee's approval was obtained. During the period of 2009-2016 a total of 92373 people (58.4\% women and $41.6 \%$ men) were evaluated. This study included men aged 40-54 and women aged 50-64 without overt cardiovascular disease. Subjects were divided into two groups by their dyslipidemia status-dyslipidemic and non-dyslipidemic. Their risk factors and lipid profile assessment were obtained and used for statistical analysis. Study data has been further analyzed by dividing all subjects into appropriate groups by the age, men: 4044 years, 45-49 years, 50-54 years and women: 50-54 years, $55-59$ years, $60-64$ years.

Dyslipidemia was considered if serum total cholesterol (TC) $>5 \mathrm{mmol} / \mathrm{L}$, or low-density lipoprotein-cholesterol (LDL-C) $>3 \mathrm{mmol} / \mathrm{L}$, or high-density lipoprotein cholesterol $(\mathrm{HDL}-\mathrm{C})<1.0 \mathrm{mmol} / \mathrm{L}$ in men and $<1.2 \mathrm{mmol} / \mathrm{L}$ in women, or triglycerides (TG) $>1.7 \mathrm{mmol} / \mathrm{L}$. Metabolic syndrome (MS) was assessed according to the National Cholesterol Education Program III modified criteria [15]. Arterial hypertension $(\mathrm{AH})$ was defined as systolic blood pressure $\geq 140 \mathrm{mmHg}$ and/or diastolic blood pressure $\geq 90 \mathrm{mmHg}$, or the diagnosis of hypertension was documented in a medical record. Obesity was identified whenever body mass index (BMI) $\geq 30$ and abdominal obesity was determined when waist circumference was $>102 \mathrm{~cm}$ for men and $>88 \mathrm{~cm}$ for women. The overall cardiovascular risk was calculated according to the risk estimation Systematic Coronary Risk Evaluation (SCORE) system [16]. A detailed description of the Lithuanian High Cardiovascular Risk programme protocol is presented in Laucevicius, et al. paper [17].

\section{Statistical analysis}

For continuous variables, the following descriptive statistics are reported: Means, standard deviations (SD) and $95 \%$ confidence interval $(\mathrm{Cl})$. For categorical data frequencies are reported. In the case of dichotomous categorical variables, we also provide confidence intervals for proportions of interest (e.g. diabetes, smoking, etc.). These intervals were obtained using the relationship between beta and binomial distributions. Categorical variables were compared with the help of the chisquare test. All reported $p$-values are two-tailed. The level of significance was set to 0.05 .

\section{Results}

\section{Sample characteristics and cardiovascular risk profi- le of subjects with and without dyslipidemia}

This study included 92373 adults without overt cardiovascular disease-53961 (58.4\%) women and 38412 (41.6\%) men. The average age of the sample group was 52.15 ( \pm 6.21 ) years. Women and men varied in age because of different study enrollment criteria. Baseline characteristics and prevalence of cardiovascular risk factors of the whole study population are shown in Table 1. $81.7 \%$ of subjects had TC $>5 \mathrm{mmol} / \mathrm{L}, 79.3 \%$ had LDL-C $>3 \mathrm{mmol} / \mathrm{L}, 30.4 \% \mathrm{had}$ TG $>1.7 \mathrm{mmol} / \mathrm{L}$ and $13.7 \%$ had low HDL-C $<1.0 \mathrm{mmol} / \mathrm{L}$ in men and $<1.2$ $\mathrm{mmol} / \mathrm{L}$ in women). Any type of dyslipidemia was diagnosed in $89.7 \%$ of middle-aged adults without overt cardiovascular disease. Group with dyslipidemia consists of 82893 (89.7\%) subjects and group without dyslipidemia includes $9480(10.3 \%)$ adults. All the major risk factors, including $\mathrm{AH}$, abdominal obesity, MS, DM and obesity, except for smoking, were more prevalent in patients with dyslipidemia compared to patients without it $(p$ $<0.001$ ) (Table 1). Average SCORE index of the whole study population was 1.87 , patients with dyslipidemia had higher SCORE compared to control group (Table 1).

\section{Cardiovascular risk assessment in middle-aged men with and without dyslipidemia}

This study included 38412 men aged 40-54: 33403 (87.0\%) with dyslipidemia and 5009 (13.0\%) without dyslipidemia. Mean value of TC in men was $6.07 \pm 1.10$ $\mathrm{mmol} / \mathrm{l}, \mathrm{LDL}-\mathrm{C}-3.92 \pm 0.98 \mathrm{mmol} / \mathrm{l}, \mathrm{HDL}-\mathrm{C}-1.39 \pm 0.47$ $\mathrm{mmol} / \mathrm{l}$ and TG $-1.86 \pm 1.45 \mathrm{mmol} / \mathrm{l}$. Prevalence of different cardiovascular risk factors in dyslipidemic and non-dyslipidemic men is presented in Figure 1. Men with dyslipidemia had all main risk factors, except smoking, significantly more often compared to males with- 
Table 1: Baseline characteristics and trends of cardiovascular risk factors in study population.

\begin{tabular}{|c|c|c|c|c|c|c|c|}
\hline & \multicolumn{2}{|c|}{ Total $(n=92373)$} & \multicolumn{2}{|c|}{$\begin{array}{l}\text { Patients with } \\
\text { dyslipidemia }(n=82893)\end{array}$} & \multicolumn{2}{|c|}{$\begin{array}{l}\text { Patients without } \\
\text { dyslipidemia }(n=9480)\end{array}$} & \multirow[t]{2}{*}{ p-value } \\
\hline & Mean & SD & Mean & SD & Mean & SD & \\
\hline Age (years) & 52.15 & 6.21 & 52.34 & 6.20 & 50.54 & 6.05 & $<0.001$ \\
\hline Waist circumference (cm) & 93.72 & 13.52 & 94.07 & 13.53 & 90.64 & 13.08 & $<0.001$ \\
\hline BMI $\left(\mathbf{k g} / \mathrm{m}^{2}\right)$ & 28.60 & 5.41 & 28.78 & 5.39 & 27.04 & 5.38 & $<0.001$ \\
\hline SBP $(\mathrm{mmHg})$ & 133.52 & 16.33 & 133.87 & 16.39 & 130.43 & 15.44 & $<0.001$ \\
\hline DBP (mmHg) & 82.76 & 9.48 & 82.95 & 9.50 & 81.15 & 9.14 & $<0.001$ \\
\hline HR (beats/min.) & 71.95 & 8.78 & 72.00 & 8.78 & 71.50 & 8.72 & $<0.001$ \\
\hline Fasting glucose (mmol/l) & 5.52 & 1.22 & 5.54 & 1.23 & 5.35 & 1.08 & $<0.001$ \\
\hline TC (mmol/l) & 6.08 & 1.21 & 6.28 & 1.12 & 4.40 & 0.45 & $<0.001$ \\
\hline LDL-C (mmol/l) & 3.87 & 1.08 & 4.04 & 1.00 & 2.42 & 0.43 & $<0.001$ \\
\hline HDL-C (mmol/l) & 1.54 & 0.46 & 1.54 & 0.47 & 1.58 & 0.37 & $<0.001$ \\
\hline TG (mmol/l) & 1.59 & 1.16 & 1.66 & 1.19 & 0.93 & 0.31 & $<0.001$ \\
\hline Non-HDL-C & 4.54 & 1.21 & 4.74 & 1.11 & 2.83 & 0.48 & $<0.001$ \\
\hline TG/HDL & 1.22 & 1.55 & 1.29 & 1.62 & 0.63 & 0.28 & $<0.001$ \\
\hline SCORE index & 1.87 & 1.68 & 1.95 & 1.71 & 1.20 & 1.18 & $<0.001$ \\
\hline Frequencies & $n$ & $\%$ & $\mathrm{~N}$ & $\%$ & $n$ & $\%$ & \\
\hline DM (\%) & 9897 & $10.7 \%$ & 9207 & $11.1 \%$ & 690 & $7.3 \%$ & $<0.001$ \\
\hline $\mathrm{AH}(\%)$ & 50317 & $54.5 \%$ & 46216 & $55.8 \%$ & 4101 & $43.3 \%$ & $<0.001$ \\
\hline Abdominal obesity (\%) & 40408 & $43.7 \%$ & 37547 & $45.3 \%$ & 2861 & $30.2 \%$ & $<0.001$ \\
\hline Smoking (\%) & 21218 & $23.0 \%$ & 18703 & $22.6 \%$ & 2515 & $26.5 \%$ & $<0.001$ \\
\hline MS (\%) & 29094 & $31.5 \%$ & 28219 & $34.0 \%$ & 875 & $9.2 \%$ & $<0.001$ \\
\hline$R F \geq 3(\%)$ & 53971 & $58.4 \%$ & 49819 & $60.1 \%$ & 4152 & $43.8 \%$ & $<0.001$ \\
\hline Familial CHD (\%) & 24025 & $26.0 \%$ & 21837 & $26.3 \%$ & 2188 & $23.1 \%$ & $<0.001$ \\
\hline Unbalanced diet (\%) & 56800 & $61.5 \%$ & 51783 & $62.5 \%$ & 5017 & $52.9 \%$ & $<0.001$ \\
\hline Insufficient physical activity (\%) & 47268 & $51.2 \%$ & 43074 & $52.0 \%$ & 4194 & $44.2 \%$ & $<0.001$ \\
\hline BMI < $25\left(\mathrm{~kg} / \mathrm{m}^{2}\right)(\%)$ & 24891 & $26.9 \%$ & 21037 & $25.4 \%$ & 3854 & $40.7 \%$ & $<0.001$ \\
\hline BMI 25-30 $\left(\mathrm{kg} / \mathrm{m}^{2}\right)(\%)$ & 35589 & $38.5 \%$ & 32209 & $38.9 \%$ & 3380 & $35.7 \%$ & $<0.001$ \\
\hline BMI 30-40 (kg/m²) (\%) & 28778 & $31.2 \%$ & 26776 & $32.3 \%$ & 2002 & $21.1 \%$ & $<0.001$ \\
\hline BMI > $40\left(\mathrm{~kg} / \mathrm{m}^{2}\right)(\%)$ & 3115 & $3.4 \%$ & 2871 & $3.5 \%$ & 244 & $2.6 \%$ & $<0.001$ \\
\hline
\end{tabular}

SD: Standard deviation; BMI: Body mass index; SBP: Systolic blood pressure; DBP: Diastolic blood pressure; HR: Heart rate; TC: Total cholesterol; LDL-C: Low density lipoprotein cholesterol; HDL-C: High density lipoprotein cholesterol; TG: Triglycerides; DM: Diabetes mellitus; AH: Arterial hypertension; MS: Metabolic syndrome; RF: Risk factors; CHD: Coronary heart disease.

out dyslipidemia: $\mathrm{AH}(49.6 \%$ vs. $36.6 \%, \mathrm{p}<0.001)$, DM $(10.8 \%$ vs. $6.6 \%, p<0.001)$, abdominal obesity $(30.1 \%$ vs. $16.2 \%, p<0.001)$, MS $(29.8 \%$ vs. $4.8 \%, p<0.001)$ and obesity ( $30.3 \%$ vs. $16.1 \%, p<0.001)$. The prevalence of $\mathrm{DM}, \mathrm{AH}$, abdominal obesity, MS and obesity increased with age in both dyslipidemic and non-dyslipidemic men groups. Males with dyslipidemia had higher prevalence of $\mathrm{DM}, \mathrm{AH}$, abdominal obesity, $\mathrm{MS}$ and obesity in all age groups in comparison with control group (Figure 1). Smoking was more prevalent in men aged 40-54 without dyslipidemia compared to group with dyslipidemia (41.8\% vs. $40.3 \%, p<0.001)$. The highest frequency of smoking in males without dyslipidemia was observed in $45-49$ year-olds $(43.8 \%)$ followed by $50-55 y$ ( $42.4 \%)$ and $40-44 y$ (39.6\%) groups. Prevalence of smoking was lower in men older than 50 years compared to younger males in both dyslipidemic and non-dyslipidemic groups (Figure 1). Also, men with dyslipidemia tended to have family history of CHD, unbalanced diet and insufficient physical activity more often compared to men without dyslipidemia $(23.9 \%$ vs. $20.6 \%, p<0.001 ; 65.5 \%$ vs. $54.1 \%, p<0.001 ; 47.3 \%$ vs. $39.5 \%, p<0.001$, respectively).

\section{Cardiovascular risk assessment in middle-aged wo- men with and without dyslipidemia}

This study included 53961 women aged 50-64: 49490 (91.7\%) with dyslipidemia and 4471 (8.3\%) without dyslipidemia. Mean laboratory values of women were: TC $-6.41 \pm 1.11 \mathrm{mmol} / \mathrm{l}, \mathrm{LDL}-\mathrm{C}-4.12 \pm 1.01 \mathrm{mmol} / \mathrm{l} \mathrm{HDL}-\mathrm{C}$ $-1.63 \pm 0.45 \mathrm{mmol} / \mathrm{l}$ and TG $-1.53 \pm 0.96 \mathrm{mmol} / \mathrm{l}$. Prevalence of different cardiovascular risk factors in dyslipidemic and non-dyslipidemic women of different age is shown on (Figure 2). Women aged 50-64 with dyslipidemia had all main cardiovascular risk factors significantly more frequently compared to females without dyslipidemia (DM (11.3\% vs. 8.0\%, p < 0.001), AH (59.9\% vs. $50.7 \%, p<0.001)$, abdominal obesity $(55.6 \%$ vs. $45.8 \%, p<0.001)$, smoking (10.6\% vs. $9.4 \%, p<0.001)$, MS $(36.9 \%$ vs. $14.2 \%, p<0.05)$ and obesity $(39.5 \%$ vs. $32.1 \%, p<0.001)$. The prevalence of $\mathrm{DM}, \mathrm{AH}$, abdominal obesity, MS and obesity increased with age in both dyslipidemic and non-dyslipidemic groups. Subjects with dyslipidemia had higher prevalence of DM, AH, abdominal obesity, MS and obesity in all age groups in comparison with control group (Figure 2). Women with dyslipidemia reported smoking more often in all age groups com- 


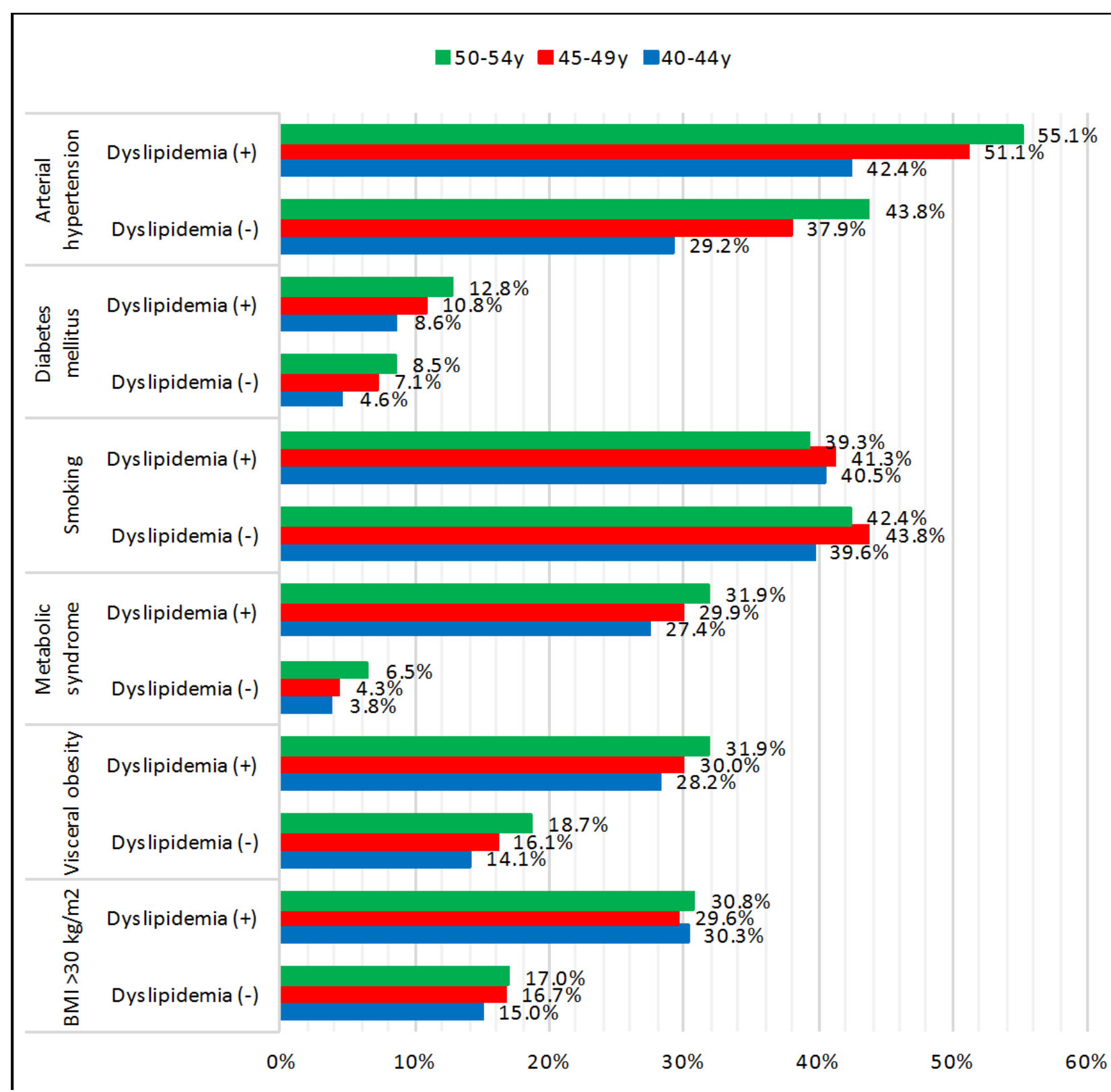

Figure 1: Prevalence of different cardiovascular risk factors in men of different age with and without dyslipidemia.

pared to women without dyslipidemia $(p<0.001)$. Frequency of smoking was lower in older women in both dyslipidemic and non-dyslipidemic groups compared to younger females (Figure 2).

\section{Dyslipidemia and concomitant risk factors}

Adults with dyslipidemia more often had $\geq 3$ concomitant risk factors in comparison with control group $(60.1 \%$ vs. $43.8 \%, p<0.001)$. Across the study population adults without dyslipidemia tended to have less risk factors while women and men with dyslipidemia had bigger number of cardiovascular risk factors (Figure 3 ). $7.5 \%$ of dyslipidemic and $13.2 \%$ of non-dyslipidemic patients did not have any other conventional risk factors. The distribution of the number of cardiovascular risk factors in study cohort is presented in (Figure 3).

\section{Discussion}

Numerous studies have established dyslipidemia [18], arterial hypertension [19], smoking [20] and diabetes mellitus [21] as main independent cardiovascular risk factors. Modifying them is proven to be the key approach to lower cardiovascular mortality $[7,22,23]$. More than $90 \%$ of acute coronary events occur in individuals with at least one expressed risk factor [24]. Dyslipidemia was responsible for $15.1 \%$ of CVD death risk in the EURIKA population [25]. The prevalence of dyslipidemia differs widely according to social, economic, ethnic and cultural aspects of specific population groups. It varies between $34.0 \%-41.9 \%$ in China [26,27], an estimated $53.0 \%$ of adults in the USA [28], 76.4\% in German adults [29] and $79.0 \%$ in India [30]. According to previous studies in Lithuania, hypercholesterolemia was present in $51.3 \%$ women and $52.2 \%$ men aged $25-64$ years (CINDI) and $81 \%$ men and $87 \%$ women aged $35-64$ in MONICA study [31,32]. In our study, prevalence of dyslipidemia in middle-aged Lithuanians was $89.5 \%$ in 2016 , slightly increasing from 2009 (89.1\%) as reported by LitHiR 


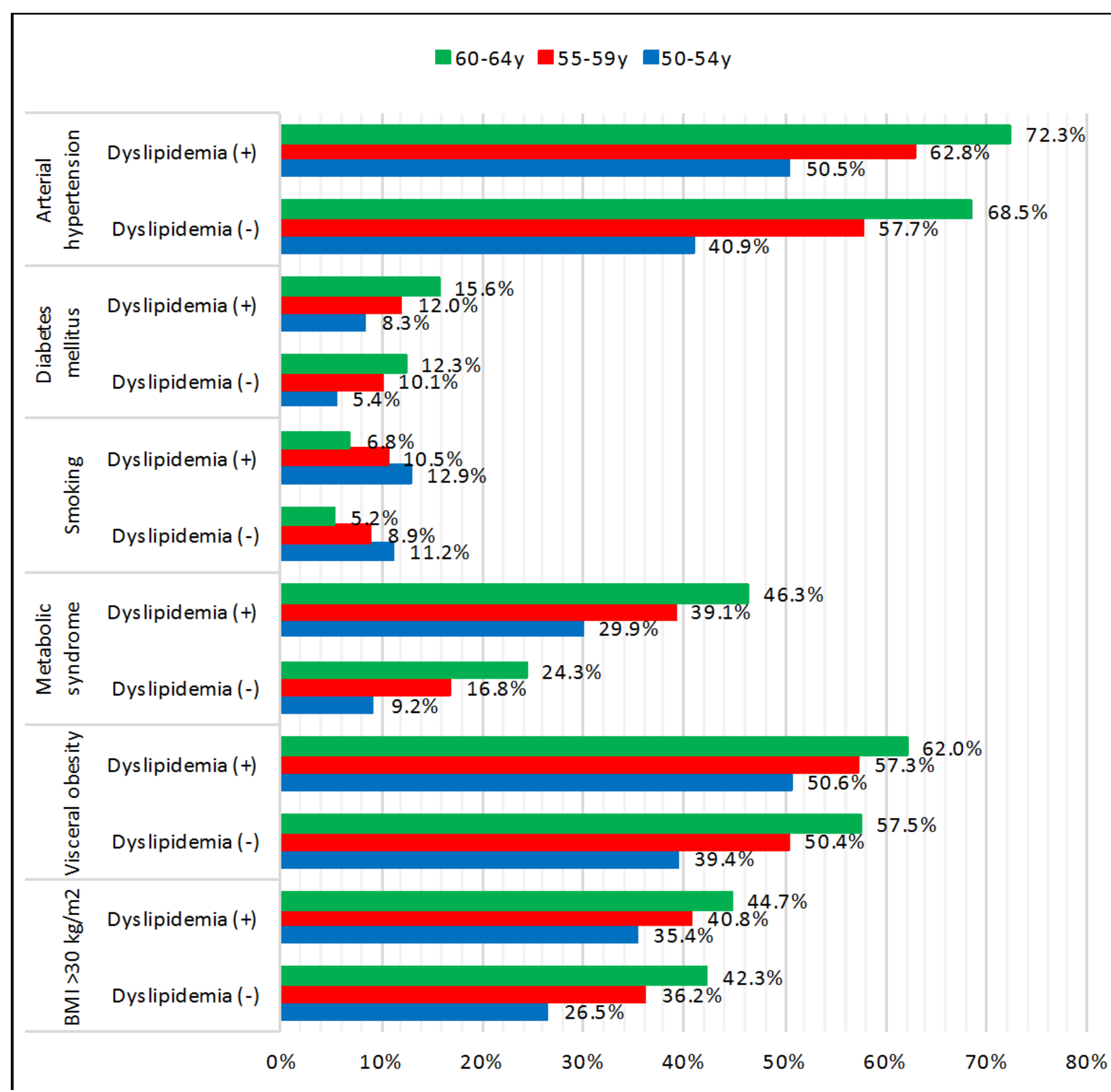

Figure 2: Prevalence of different cardiovascular risk factors in women of different age with and without dyslipidemia.

programme. This data was consistent with the results of EURIKA study where prevalence of dyslipidemia was $89.4 \%$ in primary prevention centers across Europe [25].

Cigarette smoking is one of the most important modifiable cardiovascular risk factors as it accounts for about $36 \%$ of the population attributable risk of acute myocardial infarction [33]. Smoking is related to alterations in serum lipid profile, especially with reduction low HDL-C $[34,35]$. Some of the previous studies reported that smoking causes an increase in TC, LDL-C, triglycerides, while other studies have presented results of smoking decreasing levels of TC and LDL-C [36,37]. Possible reasons for these inconsistencies of studies' results could be ethnic differences, age, gender, different diet, lifestyle and other factors [38]. Our study found the trend of higher prevalence of smoking in non-dyslipidemic men gender-specific, as men without dyslipidemia smoked significantly more often compared to men with dyslipidemia, while women with dyslipidemia smoked more frequently compared to non-dyslipidemic females. Some of researchers have suggested that association of smoking with the risk of dyslipidemia is stronger in women than in men and women who smoke could be more susceptible to develop dyslipidemia than men smokers [34].

The prevalence of obesity, MS and type 2 diabetes is rising at alarming rates and increasing the cost of obesity-related medical care [39]. Research referring to association between obesity and dyslipidemia is not definite: Some studies found that dyslipidemia correlated with $\mathrm{BMI}$ in men and waist circumference in women [40] while others described associations between waist circumference and dyslipidemia in both males and females whereas relationship between $\mathrm{BMI}$ and abnormal lipid levels was significant only in women $[41,42]$. Our study showed that subjects with dyslipidemia tended to have MS as well as abdominal obesity significantly more often in comparison with control group. With increas- 


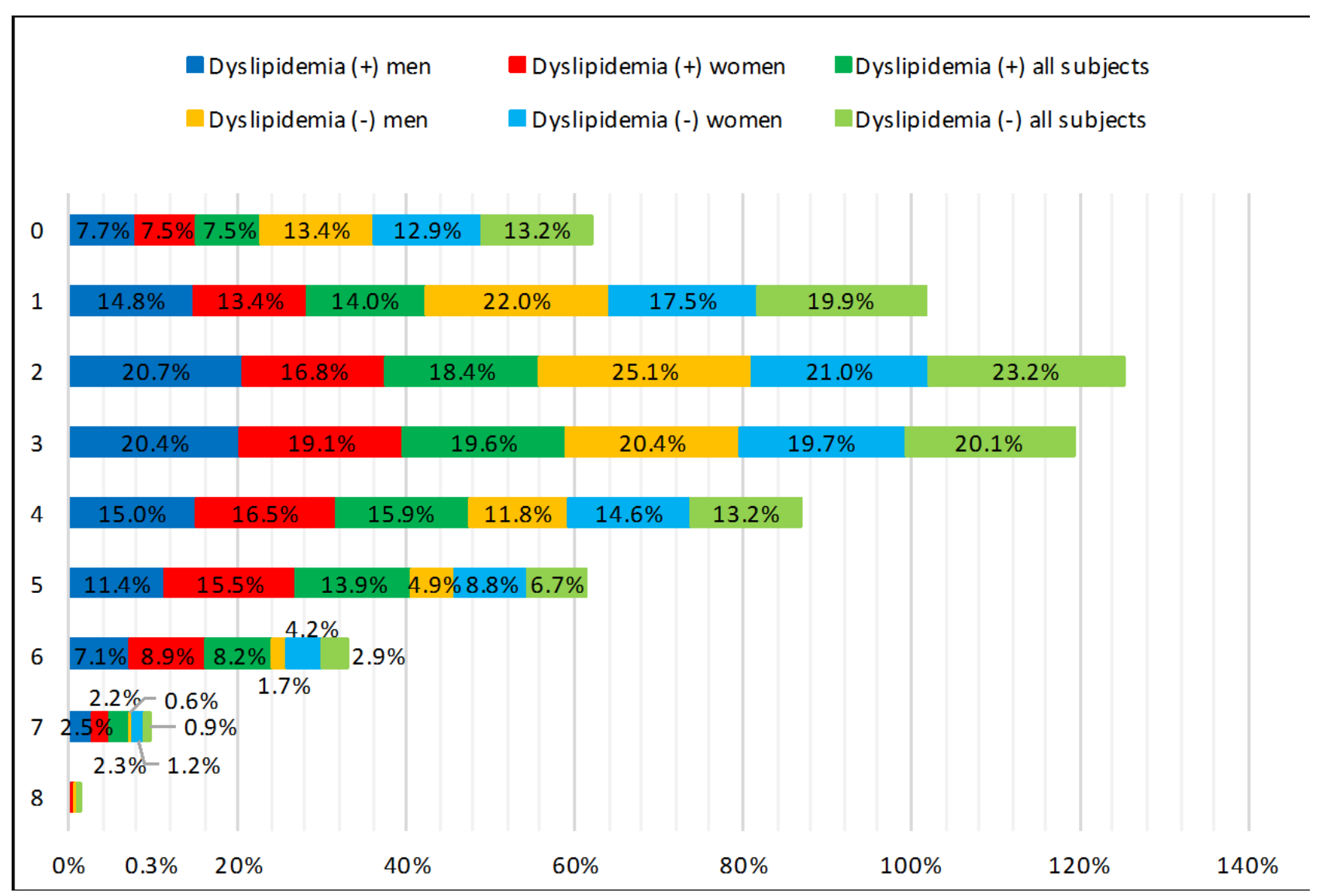

Figure 3: Distribution of number of cardiovascular risk factors in study population.

ing overweight and obesity class, there is an increase in the frequency of dyslipidemia: Nguyen, et al. found that prevalence of dyslipidemia was $8.9 \%$ in normal weight $(\mathrm{BMI}<25)$ adults and $19 \%$ in obesity class III (BMI $\geq 40)$ with highest prevalence of dyslipidemia in obesity class II (BMI 35-39.9) (20.6\%) [43]. In our study population, adults with dyslipidemia most often were overweight (38.9\%), followed by obesity class I-II (32.3\%), subjects with normal weight $(25.4 \%)$ and obesity class III (3.5\%). Diabetes is associated with atherogenic dyslipidemia, which could be one of the major determinants of high cardiovascular risk in patients with DM [44]. In this study, adults with dyslipidemia had DM more often compared to non-dyslipidemic subjects. Therefore, managing diabetic dyslipidemia requires an integrated approach: Lifestyle changes and combined pharmacological interventions are the most important treatment strategies [45].

Dyslipidemia and hypertension are the two most prevalent as well as most commonly co-existing major cardiovascular risk factors $[9,46]$. Abnormal lipid levels are one of the earliest metabolic disturbances in adults with hypertension, occurring in more than one-third of hypertensive patients [46]. Dyslipidemia increases cardiovascular risk more than twice for subjects with hypertension confirming that risk factors interact with each other $[47,48]$. According to previous studies analyzing LitHiR data, dyslipidemia was present in $91.5 \%$ of patients with $\mathrm{AH}$ [14]. In our study, prevalence of hy- pertension in the whole study population was $54.5 \%$ (55.8\% of dyslipidemic patients). Prevalence of dyslipidemia in Lithuania (89.7\%) is estimated to be higher than prevalence of hypertension while $\mathrm{AH}$ remains the most common risk factor for both developed and still developing countries worldwide $[49,50]$.

The impact of individual risk factors is well established but evaluation of cardiovascular risk requires assessment of multiple risk factors as clustering of CVD risk factors leads to higher risk of developing cardiovascular events by having synergistic, rather than additive, effects on total risk $[3,51,52]$. According to study by $\mathrm{Wu}$, et al. percentage of subjects with two or more cardiovascular risk factors varied from $36.0 \%$ in young men to $67.4 \%$ in males aged $50-59$ and from $6.5 \%$ in young women to $50.3 \%$ of older (50-59 y) females [53]. Frequency of multiple risk factors increased with age in both men and women [53]. According to our data, dyslipidemia was often accompanied by other cardiovascular risk factors-almost two thirds of middle-aged subjects with dyslipidemia had three or more cardiovascular risk factors and only $7.5 \%$ had no other risk factors. While typical high-risk profile of middle-aged Lithuanian has been described as having dyslipidemia, hypertension and abdominal obesity [54], it is clear that high cardiovascular risk in Lithuania is impacted by combination of these different risk factors. Studies have shown that greater number of risk factors is related to correspondingly poorer clinical outcome [55]. Based on 
these revelations, it is clear that optimal therapeutic CVD prevention strategy requires targeting 2 or more of risk factors collectively [46].

Despite very high prevalence of dyslipidemia, frequent coexistence of several cardiovascular risk factors and high cardiovascular mortality in Lithuania, the average estimated 10-year risk of fatal CVD disease based on the SCORE equation in our study patients was moderate $(1.87 \%)$. This finding was not compatible with the EURIKA study results where average 10 -year risk of CVD death was $8.2 \%$ across Europe [25]. This revelation may propose that high-risk SCORE equation could underestimate the risk in Lithuania and other Eastern European countries with extremely high rates of CVD mortality despite paper by Vikhireva, et al. showing that highrisk SCORE was a significant risk predictor in Lithuania and other Central and Eastern European countries [56]. Other possible explanation could be the SCORE index underestimating risk in patients with certain risk factors not included in the equation, such as sedentary lifestyle, visceral obesity, a family history of premature CVD, or presence of subclinical atherosclerosis $[3,25]$. This discovery could be the basis of future studies examining potential reasons for the disparity between calculated risk by SCORE equation and actual risk in our country.

To overcome the existing situation, it is essential to improve the control of multiple risk factors, which have an important role in cardiovascular pathology. There is good quality evidence of early and integrated approach to correction of dyslipidemia and we need to raise awareness about the benefit of timely detection and treatment of abnormal lipid levels.

\section{Limitations of the Study}

The present study examined a sample of men aged 40-54 years and women aged 50-64 years. A future study is needed to examine the younger and the older samples. Some risk factors, which are important in risk assessment, such as psychosocial factors, social class and others, were not taken into account. Also, dyslipidemia as defined in this study, cover broad spectrum of lipid abnormalities, so very high prevalence of this disorder was detected. Further studies are needed to evaluate prevalence of different types of dyslipidemia in this population.

\section{Conclusions}

Dyslipidemia is very common in middle-aged Lithuanians without overt cardiovascular disease. Although prevalence of cardiovascular risk factors increases with age, dyslipidemia is associated with greater probability of having diabetes mellitus, arterial hypertension, abdominal obesity, metabolic syndrome and obesity, except for smoking, in all age groups compared to adults without dyslipidemia. Men and women with dyslipidemia have a higher total number of cardiovascular risk factors which synergistically increases absolute risk of
CVD. The average 10-year risk of CVD death in patients with dyslipidemia was $1.95 \%$. Our observations emphasize the importance of properly diagnosing and treating dyslipidemia as well as other concomitant risk factors in order to reduce burden of cardiovascular disease in Lithuania.

\section{Conflict of Interest}

We have no conflict of interest to declare. This research did not receive any specific grant from funding agencies in the public, commercial, or not-for-profit sectors.

\section{Author Contributions}

All authors listed have contributed sufficiently to the project to be included as authors, and all those who are qualified to be authors are listed in the author byline. All authors have read and approved the final version of the manuscript.

\section{References}

1. (2017) Causes of death 2016. Health Information Centre of the Institute of Hygiene, Vilnius.

2. (2017) Eurostat. Causes of death - standardized death rate, 2014.

3. Piepoli MF, Hoes AW, Agewall S, Albus C, Brotons C, et al. (2016) European guidelines on cardiovascular disease prevention in clinical practice: The sixth joint task force of the european society of cardiology and other societies on cardiovascular disease prevention in clinical practice (constituted by representatives of 10 societies and by invited experts) developed with the special contribution of the European Association for Cardiovascular Prevention \& Rehabilitation (EACPR). Eur Heart J 37: 2315-2381.

4. European heart health charter. European Commission.

5. Degoma EM, Knowles JW, Angeli F, Budoff MJ, Rader DJ (2012) The evolution and refinement of traditional risk factors for cardiovascular disease. Cardiol Rev 20: 118-129.

6. Nelson RH (2013) Hyperlipidemia as a risk factor for cardiovascular disease. Prim Care 40: 195-211.

7. Baigent C, Keech A, Kearney PM, Blackwell L, Buck G, et al. (2005) Efficacy and safety of cholesterol-lowering treatment: prospective meta-analysis of data from 90,056 participants in 14 randomised trials of statins. Lancet 366 : 1267-1278.

8. Kabakci G, Koylan N, Ilerigelen B, Omer Kozan, Buyukozturk K (2008) Impact of dyslipidemia on cardiovascular risk stratification of hypertensive patients and association of lipid profile with other cardiovascular risk factors: Results from the ICEBERG study. Integr Blood Press Control 1: 5-13.

9. Dalal JJ, Padmanabhan TN, Jain P, Patil S, Vasnawala $H$ (2012) LIPITENSION: Interplay between dyslipidemia and hypertension. Indian J Endocrinol Metab 16: 240-245.

10. Granger DN, Rodrigues SF, Yildirim A, Senchenkova EY (2010) Microvascular responses to cardiovascular risk factors. Microcirculation 17: 192-205.

11. Rinkūnienė E, Laucevičius $A$, Petrulionienè Ž, Jolita Badarienẻ (2012) Lietuvos didelès kardiovaskulinès rizikos pacientų atrankos ir prevenciniu premoniu ( $\mathrm{LitHiR}$ ) programos rezultatai: Dislipidemijos paplitimas tarp vidurinio amžiaus suaugusių Lietuvos gyventojų. Medicinos Teorija ir Praktika 18: 636-642. 
12. Catapano AL, Graham I, De backer G, Wiklund O, Chapman MJ, et al. (2016) 2016 ESC/EAS Guidelines for the Management of Dyslipidaemias: The Task Force for the Management of Dyslipidaemias of the European Society of Cardiology (ESC) and European Atherosclerosis Society (EAS) Developed with the special contribution of the European Assocciation for Cardiovascular Prevention \& Rehabilitation (EACPR). Atherosclerosis 253: 281-344.

13. Dambrauskiene K, Veryga A, Klumbiene J, Petkevičiené $J$ (2010) Evaluation of smoking habits among Lithuanian adult population in 1994-2008, according to gender, age and education. Public Health 1: 31-35.

14. Rinkūnienè E, Petrulionienè Ž, Dženkevičiūtè V, Kutkienè S, Puronaitė R, et al. (2013) Tradicinių rizikos veiksnių paplitimas tarp pacientų, sergančių arterine hipertenzija. Medicinos Teorija ir Praktika 19: 124-129.

15. Expert Panel on Detection, Evaluation, and Treatment of High Blood Cholesterol in Adults (2001) Executive summary of the third report of The National Cholesterol Education Program (NCEP) expert panel on detection, evaluation, and treatment of high blood cholesterol in adults (Adult Treatment Panel III). JAMA 285: 2486-2497.

16. Conroy RM, Pyörälä K, Fitzgerald AP, Sans S, Menotti A, et al. (2003) Estimation of ten-year risk of fatal cardiovascular disease in Europe: The SCORE project. Eur Heart J 24: 987-1003.

17. Laucevicius A, Kasiulevicius V, Jatuzis D, Petrulionienè Z, Ryliškytè L, et al. (2012) Lithuanian High Cardiovascular Risk (LitHiR) primary prevention programme - rationale and design. Seminars in Cardiovascular Medicine 18: 1-6.

18. Prospective Studies Collaboration, Lewington S, Whitlock G, Clarke R, Sherliker P, et al. (2007) Blood cholesterol and vascular mortality by age, sex, and blood pressure: A meta-analysis of individual data from 61 prospective studies with 55,000 vascular deaths. Lancet 370: 1829-1839.

19. Pastor-barriuso R, Banegas JR, Damián J, Appel LJ, Guallar E (2003) Systolic blood pressure, diastolic blood pressure, and pulse pressure: An evaluation of their joint effect on mortality. Ann Intern Med 139: 731-739.

20. Doll R, Peto R, Boreham J, Sutherland I (2004) Mortality in relation to smoking: 50 years' observations on male British doctors. BMJ 328: 1519.

21. Emerging Risk Factors Collaboration, Sarwar N, Gao $P$ Seshasai SR, Gobin R, et al. (2010) Diabetes mellitus, fasting blood glucose concentration, and risk of vascular disease: A collaborative meta-analysis of 102 prospective studies. Lancet 375: 2215-2222.

22. Ettehad D, Emdin CA, Kiran A, Anderson SG, Callender $\mathrm{T}$, et al. (2016) Blood pressure lowering for prevention of cardiovascular disease and death: A systematic review and meta-analysis. Lancet 387: 957-967.

23. Pirie K, Peto R, Reeves GK, Green J, Beral V, et al. (2013) The 21st century hazards of smoking and benefits of stopping: A prospective study of one million women in the UK. Lancet 381: 133-141.

24. Vasan RS, Sullivan LM, Wilson PW, Sempos CT, Sundström J, et al. (2005) Relative importance of borderline and elevated levels of coronary heart disease risk factors. Ann Intern Med 142: 393-402.

25. Guallar E, Banegas JR, Blasco-Colmenares E, Jiménez FJ, Dallongeville J, et al. (2011) Excess risk attributable to traditional cardiovascular risk factors in clinical practice settings across Europe - The EURIKA Study. BMC Public Health 11: 704.
26. Pan L, Yang Z, Wu Y, Yin RX, Liao Y, et al. (2016) The prevalence, awareness, treatment and control of dyslipidemia among adults in China. Atherosclerosis 248: 2-9.

27. Huang Y, Gao L, Xie X, Tan SC (2014) Epidemiology of dyslipidemia in Chinese adults: Meta-analysis of prevalence, awareness, treatment, and control. Popul Health Metr 12: 28.

28. Tóth PP, Potter D, Ming EE (2012) Prevalence of lipid abnormalities in the United States: The National Health and Nutrition Examination Survey 2003-2006. J Clin Lipidol 6: 325-330.

29. Steinhagen-Thiessen E, Bramlage P, Lösch C, Hauner $\mathrm{H}$, Schunkert $\mathrm{H}$, et al. (2008) Dyslipidemia in primary care--prevalence, recognition, treatment and control: Data from the German Metabolic and Cardiovascular Risk Project (GEMCAS). Cardiovasc Diabetol 7: 31

30. Joshi SR, Anjana RM, Deepa M, Pradeepa R, Bhansali A, et al. (2014) Prevalence of dyslipidemia in urban and rural India: The ICMR-INDIAB study. PLoS One 9: e96808

31. Grabauskas V, Klumbienè J, Petkevičienè J, Petrauskiene A, Tamosiūnas A, et al. (2008) Risk factors for noncommunicable diseases in Lithuanian rural population: CINDI survey 2007. Medicina (Kaunas) 44: 633-639.

32. Domarkienè $S$, Tamošiūnas A, Rèklaitienè R, Sidlauskiene $\mathrm{D}$, Jureniene $\mathrm{K}$, et al. (2003) Trends in main cardiovascular risk factors among middle-aged Kaunas population between 1983 and 2002. Medicina (Kaunas) 39: 1193-1199.

33. Yusuf S, Hawken S, Ounpuu S, Dans T, Avezum A, et al. (2004) Effect of potentially modifiable risk factors associated with myocardial infarction in 52 countries (the INTERHEART study): Case-control study. Lancet 364: 937-952.

34. Lee MH, Ahn SV, Hur NW, Choi DP, Kim HC, et al. (2011) Gender differences in the association between smoking and dyslipidemia: 2005 Korean National Health and Nutrition Examination Survey. Clin Chim Acta 412: 1600-1605.

35. Mouhamed HD, Ezzaher A, Neffati F, Gaha L, Douki W, et al. (2013) Association between cigarette smoking and dyslipidemia. IBS 28: 195-200.

36. Schuitemaker GE, Dinant GJ, van der Pol GA, van Wersch JW (2002) Relationship between smoking habits and low-density lipoprotein-cholesterol, high-density lipoprotein-cholester$\mathrm{ol}$, and triglycerides in a hypercholesterolemic adult cohort, in relation to gender and age. Clin Exp Med 2: 83-88.

37. Kuzuya M, Ando R, Iguchi A, Shimokata H (2006) Effect of smoking habit on age-related changes in serum lipids: A cross-sectional and longitudinal analysis in a large Japanese cohort. Atherosclerosis 185: 183-190.

38. Tan XJ, Jiao GP, Ren YJ, Gao XR, Ding Y, et al. (2008) Relationship between smoking and dyslipidemia in western Chinese elderly males. J Clin Lab Anal 22: 159-163.

39. Wyatt SB, Winters KP, Dubbert PM (2006) Overweight and obesity: Prevalence, consequences, and causes of a growing public health problem. Am J Med Sci 331: 166-174.

40. Nahar N, Dubey S, Joshi A, Sameer P, Sharma VK (2012) Association of anthropometric indices of obesity with diabetes, hypertension and dyslipidemia: A study from central India. Indian Journal of Medical Specialities 3: 6-11.

41. Onat A, Ayhan E, Hergenc G, Can G, Barlan MM (2009) Smoking inhibits visceral fat accumulation in Turkish women: Relation of visceral fat and body fat mass to atherogenic dyslipidemia, inflammatory markers, insulin resistance, and blood pressure. Metabolism 58: 963-970. 
42. Paccaud $F$, Schlüter-Fasmeyer $V$, Wietlisbach $V$, Bovet $P$ (2000) Dyslipidemia and abdominal obesity: An assessment in three general populations. J Clin Epidemiol 53: 393-400.

43. Nguyen NT, Magno CP, Lane KT, Hinojosa MW, Lane JS (2008) Association of hypertension, diabetes, dyslipidemia, and metabolic syndrome with obesity: Findings from the National Health and Nutrition Examination Survey, 1999 to 2004. J Am Coll Surg 207: 928-934.

44. Taskinen MR, Boren J (2015) New insights into the pathophysiology of dyslipidemia in type 2 diabetes. Atherosclerosis 239: 483-495.

45. Wu L, Parhofer KG (2014) Diabetic dyslipidemia. Metabolism 63: 1469-1479.

46. Chapman MJ, Sposito AC (2008) Hypertension and dyslipidaemia in obesity and insulin resistance: Pathophysiology, impact on atherosclerotic disease and pharmacotherapy. Pharmacol Ther 117: 354-373.

47. Wong ND, Lopez V, Tang S, Williams GR (2006) Prevalence, treatment, and control of combined hypertension and hypercholesterolemia in the United States. Am J Cardiol 98: 204-208.

48. Jackson R, Lawes CM, Bennett DA, Milne RJ, Rodgers A (2005) Treatment with drugs to lower blood pressure and blood cholesterol based on an individual's absolute cardiovascular risk. Lancet 365: 434-441.

49. Kearney PM, Whelton M, Reynolds K, Whelton PK, He J (2004) Worldwide prevalence of hypertension: A systematic review. J Hypertens 22: 9-11.
50. Kotseva K, Wood D, De backer G, De Bacquer D, Pyörälä K, et al. (2009) EUROASPIRE III: A survey on the lifestyle, risk factors and use of cardioprotective drug therapies in coronary patients from 22 European countries. Eur J Cardiovasc Prev Rehabil 16: 121-137.

51. Poulter $N$ (1999) Coronary heart disease is a multifactorial disease. Am J Hypertens 12: 92S-95S.

52. Zannad F (2008) Cardiovascular high-risk patients - treat to protect, but whom? Medscape J Med 10: S2.

53. Wu DM, Pai L, Chu NF, Sung PK, Lee MS, et al. (2001) Prevalence and clustering of cardiovascular risk factors among healthy adults in a Chinese population: The MJ Health Screening Center Study in Taiwan. Int J Obes Relat Metab Disord 25: 1189-1195.

54. Laucevičius A, Rinkūnienė E, Skorniakov V, Petrulionienè Z, Kasiulevičius V, et al. (2013) High-risk profile in a region with extremely elevated cardiovascular mortality. Hellenic $\mathrm{J}$ Cardiol 54: 441-447.

55. Thomas F, Rudnichi A, Bacri AM, Bean K, Guize L, et al. (2001) Cardiovascular mortality in hypertensive men according to presence of associated risk factors. Hypertension 37: 1256-1261.

56. Vikhireva O, Pajak A, Broda G, Malyutina S, Tamosiunas A, et al. (2014) SCORE performance in Central and Eastern Europe and former Soviet Union: MONICA and HAPIEE results. Eur Heart J 35: 571-577. 